\title{
Análise fenotípica e genotípica da virulência de Staphylococcus spp. e de sua dispersão clonal como contribuição ao estudo da mastite bovina ${ }^{1}$
}

\author{
Viviane F. Marques ${ }^{2}$, Miliane M.S. de Souza ${ }^{3 *}$, Elaine C.L. de Mendonça ${ }^{2}$, Tatiani Abreu de \\ Alencar ${ }^{4}$, Bruno Rocha Pribul2 ${ }^{2}$, Shana de M. de O. Coelho ${ }^{3}$, Mirta Lasagno ${ }^{5}$ e Elina B. Reinoso
}

\begin{abstract}
Marques V.F., Souza M.M.S., Mendonça E.C.L., Alencar T.A., Pribul B.R., Coelho S.M.O., Lasagno M. \& Reinoso E. 2013. [Phenotypic and genotypic analysis of virulence in Staphylococcus spp. and its clonal dispersion as a contribution to the study of bovine mastitis.] Análise fenotípica e genotípica da virulência de Staphylococcus spp. e de sua dispersão clonal como contribuição ao estudo da mastite bovina. Pesquisa Veterinária Brasileira 33(2):161-170. Departamento de Microbiologia e Imunologia Veterinária, Universidade Federal Rural do Rio de Janeiro, Seropédica, RJ 23890-000, Brazil. E-mail: miliane@ufrrj.br

Mastitis is an inflammation of one or more mammary glands caused mainly by bacteria, among which the genus Staphylococcus plays an important role. Bacteria belonging to this genus are known to express virulence factors which allow their persistence and spread in the host. This study aimed to evaluate the phenotypic and genotypic aspects of virulence factors in Staphylococci spp. isolates from bovine mastitis clinical cases. A total of 272 milk samples from 8 farms in the South-Fluminense region of Rio de Janeiro were analyzed. The samples underwent conventional bacterial identification, yielding 250 Staphylococci spp. isolates. These were tested for the phenotypic detection of slime production by the microplate and Congo Red Agar methods. The hemolysins production, hemolytic synergism, caseinase and DNase production were also evaluated. The isolates were then assayed through the Polymerase Chain Reaction method to detect genes associated with virulence factors such as: capsule ( $c a p 5, c a p 8)$, fibronectin $(f n b A, f n b B)$, slime (icaA, icaD) and hemolysins (hla e hlb). Regarding the number of isolates assessed, 58\% $(145 / 250)$ were identified as coagulase-negative Staphylococcus spp. and 42\% (105/250) as coagulase-positive Staphylococcus spp. The latter comprised $36.2 \%(38 / 105)$ of isolates identified as S. aureus, $11.4 \%(12 / 105)$ as $S$. intermedius and $3.8 \%(4 / 105)$ belonging to the SIG group. The hemolisin production was not significant, whereas only $6,4 \%(16 / 250)$ produced alfa hemolysis, 4,8\% (12/250) produced beta hemolysis and 1,6\% (4/250) was able to produce both. Caseinase production was observed in $66.4 \%(166 / 250)$ and slime production assayed through the microplate method was positive in 76,8\% (192/250). DNAse was detected in coagulase-negative Staphylococcus spp. (38/145) and in S. aureus $(14 / 38)$. Low association between genetic detection of icaA $(38 / 250)$ and icaD $(54 / 250)$ and slime phenotypic expression $(192 / 250)$ suggest that others genetic markers can be involved in this expression. Regarding gene amplification, the isolates did not show significant correlation between the genetic detection of icaA (38/250) and icaD $(54 / 250)$ and slime production $(192 / 250)$, indicating that other genetic markers may be involved
\end{abstract}

\footnotetext{
${ }^{1}$ Recebido em 1 de março de 2012.

Aceito para publicação em 8 de setembro de 2012.

${ }^{2}$ Curso de Pós-Graduação em Ciências Veterinárias, Universidade Federal Rural do Rio de Janeiro (UFRRJ), Seropédica, RJ 23890-000, Brasil. E-mail: vivifigueira@yahoo.com.br

${ }^{3}$ Departamento de Microbiologia e Imunologia Veterinária, UFRRJ, Seropédica, RJ. *Autor para correspondência: miliane@ufrrj.br
}

\footnotetext{
${ }^{4}$ Programa de Pós-Graduação em Ciência, Tecnologia e Inovação em Agropecuária, Universidade Federal Rural do Rio de Janeiro, Seropédica, RJ 23890-000/Universid Nacional de Rio Cuarto (UNRC), 5800 Río Cuarto, Córdoba, Argentina.

${ }^{5}$ Departamento de Microbiología e Imunología, Facultad de Ciencias Exactas, Físico-Químicas y Naturales, UNRC, 5800 Río Cuarto, Córdoba, Argentina.
} 
in this trait expression. The frequency of the occurrence of the others studied genes was of $4 \%(10 / 250)$ for cap5 and cap8, 32,8\% (82/250) for $f n b A, 4,4 \%(11 / 250)$ for $f n b B$, $19,2 \%(48 / 250)$ for hla and $18 \%(45 / 250)$ for $h l b$. The major circulating strain profile on the farms encompassed slime and caseinase producer strains. The spaA gene was found in all of the $S$. aureus isolates, presenting varying amplicons sizes, with $300 \mathrm{bp}$ being the prevalent size. The amplification of the coa gene showed nine polymorphic variants, with $600 \mathrm{bp}$ being the prevalent amplicon. The agr gene was also detected in every $S$. aureus isolate, with an amplicon of $200 \mathrm{bp}$. It was noticed that the presence or absence of the virulence genes assayed in this study were not correlated with the 6 distinct electrophoretic profiles obtained by PFGE.

INDEX TERMS: Staphylococcus spp., mastitis, virulence factors.

RESUMO.- A mastite é uma inflamação da glândula mamária causada principalmente por bactérias, dentre as quais o gênero Staphylococcus ocupa um papel importante. Bactérias pertencentes a este gênero são caracterizadas por expressar fatores de virulência que permitem sua persistência e disseminação no hospedeiro. 0 presente trabalho teve por objetivo avaliar fenogenotipicamente os fatores de virulência de isolados de Staphylococcus spp. a partir de casos de mastite bovina. Foram analisadas 272 amostras de leite provenientes de oito propriedades da região Sul-Fluminense do Estado do Rio de Janeiro. Após identificação, obteve-se um total de 250 isolados de Staphylococcus spp. Estes foram submetidos às provas fenotípicas de detecção da produção de "slime" em microplaca e em ágar vermelho congo; produção de hemolisinas e sinergismo hemolítico; produção de caseinase e DNase. Posteriormente foram submetidos à técnica de PCR para detecção dos genes de produção de cápsula (cap5 e cap8), fibronectina ( $f n b A$,e $f n b B$ ), "slime" (icaA e icaD) e hemolisinas (hla e hlb). Do total avaliado, 58\% (145/250) foi identificado como Staphylococcus spp. coagulase-negativos e 42\% (105/250) como Staphylococcus spp. coagulase-positivos, destes $36,2 \%(38 / 105)$ foram identificados como $S$. aureus, $11,4 \%(12 / 105)$ como $S$. intermedius e 3,8\% (4/105) como pertencentes ao grupo SIG. Apenas 6,4\% (16/250) dos isolados foram produtores de $\alpha$-hemólise, 4,8\% (12/250) de $\beta$-hemólise e, 1,6\% $(4 / 250)$ de $\alpha$ e $\beta$-hemólise. A produção de caseinase foi observada em $66,4 \%(166 / 250)$, e a produção de "slime" avaliada pela técnica da microplaca em 76,8\% (192/250) dos isolados, respectivamente. A DNase foi detectada em ECNs $(38 / 145)$ e $S$. aureus (14/38). Os marcadores genéticos avaliados para a produção de slime, ica $A$ e ica $D$ apresentaram nenhuma ou leve concordância com a produção fenotípica, respectivamente, utilizando o coeficiente Kappa. Tal dado parece indicar que outros marcadores genéticos podem estar envolvidos com a expressão desta característica. Os demais genes detectados com frequência de $4 \%(10 / 250)$ para cap5 e para cap8, 32,8\% (82/250) para fnbA, 4,4\% (11/250) para fnbB, 19,2\% (48/250) para hla e $18 \%(45 / 250)$ para $h l b$. 0 perfil circulante nas propriedades foi o 1: isolado produtor de "slime" e caseinase. 0 gene spaA foi positivo em todos os $S$. aureus, apresentando amplicons de tamanhos variados, sendo o tamanho prevalente o de $300 \mathrm{pb}$. A amplificação do gene coa apresentou nove tipos polimórficos distintos, sendo prevalente o amplicon de $600 \mathrm{pb}$. 0 gene agr foi detectado em todos os $S$. aureus, com amplicon de $200 \mathrm{pb}$. Foi observado que os genes de vi- rulência estudados estavam distribuídos de modo aleatório entreos 6 distintos perfis eletroforéticos obtidos através da Eletroforese em Gel de Campo Pulsado (PFGE).

TERMOS DE INDEXAÇÃO: Staphylococcus spp., mastite, fatores de virulência.

\section{INTRODUÇÃO}

As espécies de Staphylococcus spp. têm papel importante na etiologia das infecções intramamárias do gado leiteiro (Freitas et al. 2005). Destas, os Staphylococcus aureus, destacam-se entre os agentes etiológicos prevalentes neste tipo de infecção (Zafalon et al. 2008), porém, os estafilococos coagulase-negativos têm emergido como microrganismos causadores de mastite, sendo responsáveis pela perda da qualidade do leite gerando prejuízos econômicos ao produtor e a indústria leiteira (Pyorala \& Taponen 2009).

Os Staphylococcus spp. podem produzir uma série de fatores de virulência que contribuem para que a bactéria invada as defesas fagocíticas do hospedeiro, facilite a sua aderência às células epiteliais e a colonização no tecido, favorecendo a sua persistência extracelular e garantindo assim êxito em sua instalação e manutenção nos tecidos do hospedeiro (Coelho et al. 2011, Silva et al. 2007). Entre estes fatores está a produção de um mucopolissacarídeo extracelular ("slime"), que parece ajudar na aderência e colonização do microrganismo ao epitélio glandular mamário. A habilidade dos $S$. aureus aderirem à superfície do epitélio tem sido associado à produção de biofilmes, que são descritos como aglomerações de células embebidas em matriz heterogênea extracelular, resultando em estruturas tridimensionais com características fisiológicas específicas (Cerca et al. 2007, Gad et al. 2009).

Algumas espécies estafilocócicas produzem hemolisinas que são diferentes entre si de acordo com a ação lítica sobre os eritrócitos. As do tipo beta e alfa são as mais importantes na patogênese das infecções intramamárias sendo que a beta toxina é uma esfingomielinase $\mathrm{Mg}^{2+}$ - dependente que degrada a esfingomielina presente na membrana celular (Linehan et al. 2003, Park et al. 2004). Elas podem ainda apresentar um efeito hemolítico sinérgico (SHA), no qual as cepas podem ter uma ação sinérgica com outros microrganismos aumentando o potencial patogênico (Demo 1996).

A detecção da atividade da desoxirribonuclease (DNase), exoproteína que catalisa a hidrólise de ligações fosfodiéster na estrutura do DNA é importante para distinguir 
estafilococos patogênicos de não patogênicos da microbiota, sendo tão importante quanto à coagulase para a patogênese do estafilococo (Citak et al. 2003).

O desenvolvimento das mastites pode estar também associado à colonização por microrganismos produtores de caseinase. A caseína é a mais importante proteína do leite, incapaz de penetrar na membrana celular dos microrganismos, a não ser que haja a sua hidrólise pela caseinase. Logo é possível que esta enzima esteja relacionada ao início e desenvolvimento de processos inflamatórios envolvendo bactérias causadoras de mastite (Zafalon et al. 2008).

Alguns estafilococos podem apresentar a coagulase que é um importante fator de virulência, pois tem a capacidade de coagular a fibrina que se deposita ao redor da bactéria oferecendo-lhe proteção (Karahan \& Cetinkaya 2007). Os $S$. aureus apresentam ainda a "proteína A" que tem a propriedade de combinar-se ao fragmento Fc da imunoglobulina G, bloqueando a via alternativa de ativação do complemento e da subsequente opsonização e fagocitose (Gómez et al. 2007). A expressão destas proteínas extracelulares está sujeita à regulação coordenada de vários loci gênicos, onde o mais estudado é o regulador agr que envolve cinco genes $(\operatorname{agr} A, \operatorname{agr} B, \operatorname{agrC}$, agrD e hld). 0 sistema agr atua como regulador positivo de proteínas secretoras $(\alpha$ e $\beta$ hemolisinas, proteases, DNAses e estafiloquinases) e pode reprimir a transcrição dos genes que codificam a proteína A, coagulase e outras proteínas associadas à parede (Novick \& Jiang 2003).

O presente trabalho teve por objetivo avaliar feno e genotipicamente fatores de virulência em Staphylococcus spp. a partir de ambientes de produção leiteira na região Sul-Fluminense do estado do Rio de Janeiro, e observar uma possível correlação com a distribuição clonal de modo a produzir dados que possam auxiliar no entendimento da dispersão da virulência nesta região.

\section{MATERIAL E MÉTODOS}

Foram utilizadas 272 amostras de leite de vacas, pertencentes a oito propriedades situadas em municípios localizados na região Sul Fluminense e metropolitana do Estado do Rio de Janeiro (Rio Claro, Piraí, Paracambi e Seropédica). Estas foram submetidas ao isolamento primário e posterior testes de identificação feno-genotípica das espécies (Sambrook et al. 2002, Koneman et al. 2008).

Todos os isolados foram testados quanto à produção dos fatores feno-genotípicos de virulência.

A hidrólise da caseína foi testada em ágar contendo 1,5\% de ágar-ágar e $10 \%$ de leite desnatado, incubado a $37^{\circ} \mathrm{C}$ por $24 \mathrm{hs}$, no qual a presença de uma área clara rodeando a zona de crescimento bacteriano indicou reação positiva (Koneman et al. 2008).

A produção de DNase foi avaliada a partir da coloração rósea observada ao redor do crescimento bacteriano em ágar DNase, incubado a $37^{\circ} \mathrm{C}$ por 24 hs (Koneman et al. 2008).

A produção de "slime" em microplaca foi avaliada quantitativamente através de modificações na metodologia proposta por Christensen et al. (1985) e Cucarella et al. (2001). Alíquotas de 0,2 mL da suspensão bacteriana obtida pela inoculação da cultura primária em caldo tripticase soja (TSA - Britania) contendo $0,24 \%$ de glicose e incubada a $37^{\circ} \mathrm{C}$ por $24 \mathrm{~h}$, foram inoculadas em microplacas de poliestireno estéreis com 96 poços contendo o mesmo caldo e incubadas por 24 horas à $37^{\circ} \mathrm{C}$ sem agitação. Após incu- bação, os poços foram lavados 2 vezes com $200 \mu \mathrm{L}$ de solução salina estéril, secos em estufa à $65^{\circ} \mathrm{C}$ por $1 \mathrm{~h}$ e corado com $200 \mu \mathrm{L}$ de safranina $1 \%$ por $15 \mathrm{~min}$. Os poços foram lavados três vezes com água destilada e secos à temperatura ambiente. A absorbância foi determinada à 490nm em leitor de ELISA (BIO RAD MODEL 680). Poços não inoculados contendo caldo TSA com $0,24 \%$ de glicose serviram como controle negativos. Os testes foram realizados em triplicata, a leitura avaliada em momentos diferentes (no mesmo dia em que foi feita a coloração: 0DPC; um dia após a coloração: 1DPC; e sete dias após a coloração: 7DPC) e uma média foi retirada dos valores obtidos em cada dia de leitura. Foram consideradas produtoras de biofilmes cepas que apresentaram valores de absorbância maiores que 0,1 (Vasudevan et al. 2003, Oliveira et al. 2006). A intensidade da produção - de "slime" foi escalonada da seguinte maneira: forte $(>0,3)$, moderada $(>0,2$ e $<0,3)$ e fraca $(>0,1$ e $<0,2)$. A produção de hemolisinas e SHA foi avaliada por cultivo em ágar sangue de carneiro (Demo, 1996).

A extração do DNA bacteriano foi realizada segundo protocolo padronizado em nosso laboratório. Colônias foram crescidas em $5 \mathrm{~mL}$ de caldo BHI (MERCK) por $18 \mathrm{hs}$ a $37^{\circ} \mathrm{C}$, para posterior centrifugação a $14.000 \mathrm{rpm}$ por $1 \mathrm{~min}$, e lavada com $500 \mu \mathrm{l}$ de tampão TE por duas vezes e recentrifugado. 0 pellet foi ressuspendido em $250 \mu \mathrm{l}$ de tampão de extração ( $\mathrm{NaCl} 150 \mathrm{mM}$; Tris-HCl $100 \mathrm{mM}$ e EDTA 20mM), adicionado lisostafina (SIGMA) para concentração final de $20 \mu \mathrm{g} / \mathrm{ml}(5 \mu \mathrm{l}$ de lisostafina $-1 \mathrm{mg} / \mathrm{ml})$ e incubado à $37^{\circ} \mathrm{C}$ por 30 minutos. A lise foi completada por adição de SDS 1\% para concentração final de $3 \mathrm{mg} / \mathrm{ml}$, incubação em banho-maria a $50^{\circ} \mathrm{C}$ por 1 hora e posteriormente $-20^{\circ} \mathrm{C}$ por $10 \mathrm{~min}$. Após centrifugação a $14.000 \mathrm{rpm}$ por $10 \mathrm{~min}$, o sobrenadante foi transferido para um novo microtubo. Foi adicionado a este o mesmo volume de clorofórmio:álcool isoamílico (24:1) e misturado por inversão por $5 \mathrm{~min}$. Após nova centrifugação a $14.000 \mathrm{rpm}$ por $1 \mathrm{~min}$, o sobrenadante foi transferido para um novo microtubo, adicionado $\mathrm{NaCl}$ para concentração final de $0,3 \mathrm{M}$ e misturado por inversão, acrescentado 2 volumes de etanol $100 \%$ e também misturado por inversão, seguido de incubação a $-20^{\circ} \mathrm{C}$ por 2 horas ou overnight. Após isto, procedeu-se a centrifugação a $14.000 \mathrm{rpm}$ por $30 \mathrm{~min}$ e descarte do sobrenadante, o pellet foi lavado com $500 \mu$ l de etanol $70 \%$ e colocado para secar à temperatura ambiente. 0 pellet foi ressuspendido em $30 \mu \mathrm{l}$ de água mili-Q.

A análise da Reação em Cadeia da Polimerase (PCR) foi realizada utilizando os iniciadores e programas de amplificação descritos no Quadro 1. A reação foi preparada para um volume final de $20 \mu \mathrm{L}$, contendo tampão $1 \mathrm{X}\left(10 \mathrm{mM}\right.$ Tris- $\mathrm{HCl}, 2,0 \mathrm{mM} \mathrm{MgCl}{ }_{2}$, $50 \mathrm{mM} \mathrm{KCl}$ e $0,1 \%$ Triton X-100, pH 9.0), 0,5mM de cada iniciador (BIONEER), 0,2 mM de dNTP (FERMENTAS), 2 U de DreamTaq ${ }^{\text {TM }}$ Green DNA Polimerase (FERMENTAS), $2 \mu$ do DNA extraído e água mili-Q para completar o volume (SAMBROOK et al., 2002) . Os amplicons foram avaliados por eletroforese em gel de agarose 1,5\% contendo corante SYBR Green (INVITROGEN) diluído. Os géis foram visualizados em transiluminador ultra-violeta e documentados pelo câmera fotográfica (SONY - Modelo DSC-HX1), utilizando marcador de peso molecular de 100 pb (FERMENTAS).

A técnica de Eletroforese em Gel de Campo Pulsado (PFGE) para obtenção dos perfis cromossômicos de $S$. aureus foi realizada mediante modificações em metodologias descritas na literatura. Colônias puras foram ressuspendidas em tampão de suspensão (100mM Tris, 100mM EDTA, pH 7,6) até alcançar a turbidez referente ao tubo 2 da escala de McFarland. Após, foi adicionado $20 \mu \mathrm{l}$ de lisostafina a $225 \mu \mathrm{l}$ da suspensão bacteriana e incubado a $37^{\circ} \mathrm{C}$ por $30 \mathrm{~min}$. Em seguida, foi agregado $5 \mu \mathrm{l}$ de proteinase $\mathrm{K}(20 \mathrm{mg} /$ $\mathrm{ml}$ ) e $250 \mu \mathrm{l}$ de agarose de baixo ponto de fusão $1,5 \%$ a $50^{\circ} \mathrm{C}$, para confecção dos blocos, que foram solidificados a $4^{\circ} \mathrm{C}$ por $20 \mathrm{~min}$. Os blocos foram incubados em 1,5ml de tampão de digestão $(0,5 \mathrm{M}$ 
tkala et al. 2004). No Brasil, foram isolados $36 \%$ (172/477) de Staphylococcus spp. coagulase-negativos e apenas $13 \%$ (65/477) de $S$. aureus em leite bovino no estado de Pernambuco (Freitas et al. 2005).

Dentre os estafilococos coagulase-positivos identificados, a espécie $S$. aureus foi prevalente, assim como observado em trabalho desenvolvido por Santos (2006) onde a frequência de $S$. aureus foi de $43,24 \%$ entre os 74 isolados de estafilococos coagulase-positivos analisados a partir de amostras de oito propriedades leiteiras do município de Uberlândia, estado de Minas Gerais. S. aureus é reconhecido como sendo o patógeno frequentemente isolado em casos de mastite subclínica, relacionado entre os microrganismos mais contagiosos, sendo responsável por grandes prejuízos à pecuária leiteira (Ferreira et al. 2006). Bannerman (2003) destacaram a presença de outras espécies de Staphylococcus spp. coagulase-positivos, como por exemplo, $S$. intermedius como patógenos oportunistas em animais. No presente estudo a ocorrência de $S$. intermedius em quadros de mastite pode estar relacionada a presença dos cães observados próximos às instalações de produção leiteira. Coelho (2008) apontou para a existência de genes de resistência em $S$. aureus e $S$. intermedius isolados de mastite bovina sugerindo uma possível transmissão interespecífica devido a aproximação entre o bovino leiteiro e outros animais domésticos no ambiente de fazenda. Staphylococcus spp. coagulase positivos do grupo SIG tem emergido como patógeno comum de diversas infecções em humanos e animais. Este grupo caracterizado por técnicas genotípicas inclui as espécies de Staphylococcus intermedius, S. pseudintermedius e $S$. delphini, que antes eram identificados como $S$. intermedius através das técnicas fenotípicas convencionais (Bannoehr et al. 2009).

Após a detecção dos fatores de virulência (Quadro 2) foi possível observar que, $S$. aureus foi a espécie que apresentou maior diversidade na expressão fenotípica de fatores de virulência e na detecção dos genes relacionados à codifica-

\section{Quadro 2. Distribuição dos fatores de virulência nas Staphylococcus spp. isoladas de leite mastítico de propriedades leiteiras da região Sul fluminense entre outubro/2009 e março/2011}

\begin{tabular}{|c|c|c|c|c|c|c|}
\hline \multirow{2}{*}{\multicolumn{2}{|c|}{$\begin{array}{l}\text { Percentual dos fato- } \\
\text { res de Virulência** }\end{array}$}} & \multicolumn{5}{|c|}{ Staphylococcus spp.* } \\
\hline & & $\overline{\mathrm{ECN}}$ & ECP & S. aureus & S. intermedius & ECP (SIG) \\
\hline \multirow{5}{*}{$\begin{array}{l}\text { Fatores Fenotí- } \\
\text { picos }\end{array}$} & Sli & 74,5 & 84,3 & 81,6 & 58,3 & 75,0 \\
\hline & SHA & 44,0 & 31,4 & 18,4 & 16,7 & 75,0 \\
\hline & Hem & 9,0 & 9,8 & 31,6 & 16,6 & 25,0 \\
\hline & $\mathrm{DNa}$ & 26,2 & 27,5 & 36,8 & 16,7 & 0 \\
\hline & Cas & 66,9 & 66,7 & 68,4 & 66,7 & 25,0 \\
\hline \multirow{8}{*}{$\begin{array}{l}\text { Fatores Genotí- } \\
\text { picos }\end{array}$} & $i c a A$ & 4,1 & 7,8 & 63,2 & 25,0 & 25,0 \\
\hline & icaD & 8,3 & 23,5 & 63,2 & 33,3 & 25,0 \\
\hline & hla & 4,8 & 11,8 & 78,9 & 33,3 & 25,0 \\
\hline & $h l b$ & 4,1 & 11,8 & 73,7 & 33,3 & 25,0 \\
\hline & cap5 & 0,7 & 2,0 & 15,8 & 8,3 & 25,0 \\
\hline & cap8 & 1,4 & 0 & 21,1 & 0 & 0 \\
\hline & $f n b A$ & 23,4 & 31,4 & 73,7 & 25,0 & 25,0 \\
\hline & $f n b B$ & 1,4 & 2,0 & 18,4 & 8,3 & 0 \\
\hline
\end{tabular}

${ }^{*} \mathrm{ECP}=$ estafilococos coagulase-positivo, $\mathrm{ECN}=$ estafilococos coagulase-negativo, $(\mathrm{SIG})=$ estafilococos coagulase-positivo pertencentes ao grupo de Staphylococcus intermedius. ${ }^{* *}$ Sli = "slime", Hem = hemolisina, SHA $=$ sinergismo hemolítico, $\mathrm{DNa}=$ DNase, Cas $=$ caseinase . ção desses fatores. Os S. aureus têm capacidade de produzir um grande número de fatores de virulência e acredita-se que estas características possam ser responsáveis pela extraordinária capacidade de adaptação da bactéria aos diferentes nichos do organismo (Cruz 2008).

A produção de caseinase foi significativa nos isolados avaliados, com exceção do grupo SIG, sendo 66,9\% em ECN (97/145), 68,4\% em S. aureus (26/38), 66,7\% em ECP (34/51), e em S. intermedius (8/12). A caseína é a principal fonte protéica do leite e estes dados refletem a capacidade desses microrganismos assimilarem essa proteína como fonte de aminoácidos em sua nutrição. Possuir proteases, neste caso, pode ser fundamental para a sobrevivência do microrganismo no hospedeiro e não está associada à agressividade da bactéria. A produção de caseinase está diretamente relacionada à qualidade do leite, uma vez que em estudos cuja redução da proporção relativa de caseína no leite mastítico foi detectada.

A produção de DNase foi de $36,8 \%$ em $S$. aureus (14/38), $27,5 \%$ em ECP (14/51), 26,2\% em ECN (38/145), e em $16,7 \%$ S. intermedius (2/12), não sendo detectada em SIG. Portanto, foi observada uma maior produção de DNase entre $S$. aureus em concordância com a literatura (Kateete et al. 2010). Do ponto de vista da virulência, a DNase é tão importante quanto a coagulase para o estabelecimento da infecção e sua detecção distingue estafilococos patogênicos de não patogênicos da microbiota (Citak et al. 2003).

0 gene $f n b A(1279 \mathrm{pb})$ foi amplificado de $73,7 \%$ dos $S$. aureus (28/38), seguido de $31,4 \%$ dos ECPs (16/51), 25\% dos $S$. intermedius (3/12) e dos SIG (1/4) e 23,4\% dos ECNs (34/145). 0 gene fnbB (812pb) foi amplificado de 18,4\% dos $S$. aureus (7/38), seguido de $8,3 \%$ dos $S$. intermedius (1/12), $2,0 \%$ dos ECPs $(1 / 51)$ e $1,4 \%$ dos ECNs $(2 / 145)$, não tendo sido detectado em SIG. Estudos apontam para o fato de que a aderência a fibronectina não difere entre amostras com um ou dois genes de fnb (Peacock et al. 2000). Greene et al. (1995) em experimento in vitro demonstraram que cepas de $S$. aureus mutantes para fnbA ou $f n b B$ não mostraram redução significativa de adesão. No entanto, o duplo mutante $(f n b A$ e $f n b B)$ foi completamente defeituoso em se aderir à superfície.

É consenso entre os autores que a maioria das cepas isoladas de leite bovino podem ser classificadas nos tipos capsulares 5 e 8 (O'Riordam \& Lee 2004, Zhao et al. 2010). Contudo, a frequência destes tipos capsulares de bactérias isoladas de amostras de leite mastítico pode ser variável. No presente trabalho, o gene cap5 $(880 \mathrm{pb})$ foi amplificado em $25 \%$ dos SIG $(1 / 4), 15,8 \%$ de $S$. aureus $(6 / 38)$, $8,3 \%$ de $S$. intermedius (1/12), $2 \%$ dos ECPs $(1 / 51)$ e $0,7 \%$ dos ECNs(1/145). 0 gene cap8 (1147 pb) foi amplificado de $21,1 \%$ de $S$. aureus (8/38), seguido de $1,4 \%$ dos ECNs $(2 / 145)$, não tendo sido detectado em $S$. intermedius, SIG e ECP. Nos Estados Unidos e Europa foi amplificado 14,9\% (54/362) de cap5 e 27,1\% (98/362) de cap8 de Staphylococcus spp. oriundos de mastite bovina (Tollersrud et al. 2000). A presença de cap5 e cap8 pode variar de acordo com a região geográfica e possui importância diferenciada no desenvolvimento da infecção nestas regiões, não constituindo um ponto único possível de intervenção no controle 
das mastites, uma vez que tem sido proposta a imunização através destes antígenos capsulares (El-Sayed et al. 2006, Daum \& Spellberg 2011).

Após a execução da técnica de microplaca para produção de "slime" foi observada diferença significativa, utilizand o o teste de Friedman $(\mathrm{p}<0,05)$, nas leituras realizadas em diferentes tempos (0DPC, 1DPC e 7DPC). Considerando isolados positivos ou negativos para a produção de "slime" e desconsiderando a intensidade da produção, foi possível observar um número elevado de Staphylococcus spp. produtores de "slime". Um total de 84,3\% dos ECPs (43/51) foi produtor, seguido de $81,6 \%$ dos $S$. aureus (31/38), 75\% dos SIG (3/4), 74,5\% dos ECNs (108/145) e 58,3\% de $S$. intermedius (7/12), sugerindo um alto potencial destes isolados em utilizar o mucopolissacarídeo na adesão ao tecido glandular mamário. 0 "slime" facilita a adesão de Staphylococcus spp. ao tecido do hospedeiro e agregação célula-célula, favorecendo a formação do biofilme. No biofilme, as bactérias são menos suscetíveis ao tratamento por antibióticos e a ação do sistema imune inato do hospedeiro. A capacidade de formação de biofilmes é fonte de estudo tanto na medicina humana quanto veterinária e a melhor compreensão desta característica fornece subsídios para a aplicação de medidas de tratamento mais eficaz na mastite bovina (Melchior et al. 2005). A camada de "slime" dificulta a fagocitose por células do sistema imunológico do hospedeiro e está associada à infecções por ordenhadeiras mecânicas, pois este muco polissacarídeo facilita a adesão bacteriana à biomateriais, o qual não é removível mesmo após lavagens sucessivas (Dego et al. 2002).

A variação na expressão gênica produz intensidades diferentes de coloração e formação de três grupos produtores de "slime": fraco-produtor, produtor moderado e forte produtor, observáveis ao teste fenotípico de detecção de "slime" em microplaca. Em nosso estudo esta variação ocorreu em todos os grupos de Staphylococcus spp. estudados, não mostrando associação com a espécie. Dois mecanismos são propostos para a variação fenotípica: a mutação (no gene $i c a D$ e na região terminal do gene icaA) e regulação da transcrição do operon ica (Handke et al. 2007). Quanto à presença dos genes icaA (1315pb) e icaD (381pb), apenas $2,8 \%(7 / 250)$ foram positivos para ambos os genes e negativos para a produção de "slime" em microplaca. E um total de 56\% (140/250) dos isolados foram negativos para ambos os genes e positivos para a produção de "slime" em microplaca. Após calcular o coeficiente KAPPA foi possível observar uma leve concordância $(K=0,0187)$ entre a detecção do gene icaD e a expressão da característica de produção de "slime" e nenhuma concordância (K= - 0,0021) quando analisados a detecção do gene icaA e a expressão desta característica. Quando estes valores foram submetidos ao Teste de McNemar foi possível verificar que existe uma diferença significativa entre os dados obtidos na detecção fenotípica de "slime" frente a detecção dos genes icaA $(\mathrm{p} \leq 0,05)$ e icaD $(\mathrm{p} \leq 0,05)$, respectivamente. A baixa amplificação dos genes icaA e icaD em contraposição a alta expressão de "slime" pode ser explicada pela existência de outros mecanismos genéticos envolvidos na adesão e que, em análise posterior deverão ser testados como a detecção do gene bap, que é o codificador da proteína de superfície Bap cuja função é auxiliar na adesão intercelular e formação do biofilme e foi primariamente estudada em isolados provenientes de mastite bovina (Cucarella et al. 2001). Outra justificativa pode ser a presença de um fator independente do operon icaADBC que pode ser necessário para a síntese de polissacarídeo e acumulação do biofilme (Dobinski et al. 2003).

A produção de "slime", detectada pela técnica de microplaca, foi avaliada quanto a sua sensibilidade e especificidade considerando a presença de ambos os genes icaA e icaD como teste padrão, através da análise estatística realizada pelo teste do qui-quadrado. Devido à elevada positividade de produção "in vitro" a sensibilidade também se mostrou elevada (80\%). Já a especificidade foi inferior a 30\% demonstrando que esta técnica apresenta dificuldade em detectar isolados negativos. Uma das explicações plausíveis pode ser a possível deposição de corante agregado ao poliestireno causando efeito de positividade visual e detectável em leitura por espectofotometria. Porém a redução do tempo de incubação para evitar o excesso de corante depositado não é recomendada uma vez que o polissacarídeo relacionado à aderência ao substrato de poliestireno é expresso em quantidade significativa somente após incubações de 24h (Krepsky et al. 2003).

Dos isolados avaliados quanto à produção de hemolisinas, apenas 13,2\% (33/250) foram hemolíticos. Destes, 48,5\% (16/33) apresentaram hemólise total, 36,4\% (12/33) hemólise parcial e 15,1\% (5/33) hemólise total e parcial. A produção de hemolisinas está relacionada a patogenicidade das amostras de Staphylococcus spp. Larsen et al. (2002) sugerem que cepas de Staphylococcus spp. produtoras de hemólise parcial são mais virulentas ao gado que cepas não hemolíticas. A hemólise parcial, em Staphylococcus spp., é representada pela beta-hemolisina, uma enzima que apresenta atividade de esfingomielinase, destruindo membranas celulares ricas em esfingomielina, sendo tóxica para vários tipos celulares apresentando grande importância nos casos de mastite uma vez que o úbere é rico em esfingomielina (Linehan et al. 2003, Coelho et al. 2011). ECNs foram os menos produtores apresentando 91,0\% (132/145) dos isolados não-hemolíticos. Chapman et al. (1934) reportaram estafilococos que não produziam nenhum tipo de hemolisina, concluindo-se que este não seria um critério absoluto para sua patogenicidade. Silva \& Cardoso (2000) apontaram que amostras não hemolíticas também podem ser isoladas de casos de mastite bovina. Em estudo realizado com cepas de Staphylococcus spp. foi demonstrado que todas as amostras analisadas eram fracas produtoras de alfa-hemolisina. A alfa-toxina é letal e sua expressão reduzida pode estar associada a vantagens adquiridas em termos de colonização e transmissibilidade (Sabersheikh \& Saunders 2004).

0 fenômeno de sinergismo hemolítico foi positivo em $36,8 \%(92 / 250)$ dos isolados. Dentre as espécies avaliadas observou-se que $S$. aureus apresentaram baixo percentual de sinergismo hemolítico 18,4\% (7/38), enquanto ECNs apresentaram percentual de 44,1\% (64/145) de positividade. ECNs foram também o grupo de Staphylococcus spp. que apresentaram a menor produção de hemolisinas, 9,0\% 
$(13 / 145)$ apenas. Isolados não hemolíticos com produção de sinergismo podem ser portadores da delta hemolisina, a qual é expressa somente na presença da beta-hemolisina (Reinoso 2004). Acredita-se que o fenômeno de sinergismo hemolítico é independente da produção de hemolisinas, porém sua ação é considerada potencializadora para isolados que são hemolíticos, especialmente em S. aureus, pois permite uma melhor colonização do úbere por estes microrganismos (Watts 1988).

Através da técnica de PCR multiplex, os genes hla e $h l b$ (210pb e $300 \mathrm{pb}$, respectivamente) foram amplificados, sendo que apenas 3,6\% (9/250) foram produtores de hemólise total e apresentaram o gene hla, 2,8\% (7/250) foram produtores de hemólise parcial e apresentaram o gene $h l b$ e $0,8 \%(2 / 250)$ dos isolados apresentaram os genes hla e $h l b$ e foram produtores de alfa e beta hemolisinas. Em 7,2\% (18/250) dos isolados foi detectada a produção de algum tipo de hemolisina, mas não amplificou para nenhum dos genes, o que sugere o envolvimento de outros marcadores genéticos, possivelmente relacionados à expressão destas toxinas, que não foram amplificados no presente trabalho. Dos isolados avaliados, $14,4 \%$ (36/250) não expressaram hemolisina, porém foram positivos para pelo menos um gene. Este fato pode ser explicado pela não expressão dos genes nas condições "in vitro" fornecidas. E $72,4 \%(181 / 250)$ não expressaram nenhum tipo de hemolisina e não amplificaram para os genes estudados.

Todos os isolados de $S$. aureus foram positivos para o gene spaA $(\mathrm{n}=38)$. 0 gene amplificado foi referente à região $\mathrm{X}$, que consiste em um número variável de repetidos 24 pares de bases. Nenhum isolado apresentou bandas múltiplas e foi possível estabelecer 9 perfis segundo o tamanho da banda. 0 perfil predominante foi o 7 (50\%) que apresenta 12 repetições. Em trabalho desenvolvido por Coelho et al. (2011), o perfil predominante da amplificação da região $\mathrm{x}$ do gene spaA foi o amplicom com tamanho de $315 \mathrm{pb}$ com frequência de $64 \%$ (32/50) de cepas $S$. aureus oriundas de mastite bovina da região sul do estado do Rio de Janeiro. Frenay et al. (1996) determinaram que cepas com mais de $260 \mathrm{pb}$ ou 11 unidades repetidas na região $X$ tendem a ser mais epidêmicas, enquanto que a presença de 7 ou menos unidades indica circulação de cepas esporádicas. Isso se justifica pelo fato de que quanto maior o número de repetições, maior a longitude da região de união à porção Fc das imunoglobulinas, favorecendo a colonização e conseqüente infecção.

Os isolados de $S$. aureus apresentaram 9 perfis distintos para o gene coa, estabelecidos pelas repetições dos 81 pares de base, sem bandas duplas e em 68,5\% (26/38) dos amplicons foi encontrado um tamanho que variou de 600 a $800 \mathrm{pb}$. 0 gene coa amplificado de isolados de $S$. aureus provenientes de animais apresenta banda única, enquanto que em isolados de origem humana apresenta banda dupla. Estudos têm indicado que $S$. aureus isolados de reservatórios humanos e animais representam duas subpopulações que raramente sofrem infecção cruzada (Karahan \& Cetinkaya 2007). Alguns genótipos de coa são predominantes em determinados países, e estes são resistentes à fagocitose e morte por neutrófilos em detrimento daqueles com genótipos menos frequentes (Aarestrup et al. 1995). Em trabalho desenvolvido por Reinoso et al (2008) foram detectados cinco perfis com amplicons de 400pb (2/15), $500 \mathrm{pb}(3 / 15), 600 \mathrm{pb}(3 / 15), 900 \mathrm{pb}(6 / 15)$ e de $1000 \mathrm{pb}$ $(1 / 15)$ de isolados de $S$. aureus oriundos de mastite bovina na Argentina. Aslanta et al. (2007) amplificaram o gene coa de 80 isolados de $S$. aureus oriundos de mastite bovina na Turquia com tamanhos de 730-1050 pb, sendo os produtos de 730 e 970 bp os mais freqüentes $(38,8 \%$ e $41,3 \%$, respectivamente). Portanto, acredita-se que a prevalência de amplicons com tamanhos entre 600 e 900 pb envolvidos em casos de mastite bovina sugere que estes sejam os perfis mais virulentos e mais competitivos relacionados a este tipo de infecção.

Todos os isolados de $S$. aureus foram positivos para o gene rnaIII $(\mathrm{n}=38)$., e apresentaram bandas de $200 \mathrm{pb}$. Esse gene, localizado no locus agr, codifica a molécula RNAIII e regula pelo menos 15 genes que codificam fatores de virulência. Os mutantes Agr não patogênicas, são relacionados com a diminuição da síntese de toxinas extracelulares e enzimas, e são, ao mesmo tempo, relacionado a um aumento da síntese de moléculas de adesão, tais como coagulase e proteína A (Coelho et al. 2011).

Após a avaliação da frequência dos fatores de virulência analisados de forma separada e considerando as espécies identificadas, as regiões foram caracterizadas quanto à presença de isolados potencialmente virulentos (Quadro 3). Nas quatro regiões de estudo (Rio Claro, Piraí, Paracambi e Seropédica), os fatores de virulência com elevada frequência foram a produção de "slime" e de caseinase. Estes podem ser, portanto, os fatores que caracterizam as cepas circulantes nestas regiões. A região de Paracambi foi a que apresentou elevada frequência de todos os fatores de virulência quando comparado às outras regiões e uma maior detecção dos genes de fibronectina e cápsula, reflexo da alta incidência de $S$. aureus. Esta espécie, quando associada à mastite bovina, é caracterizada por apresentar uma alta variação de genes de virulência, bem como uma considerável diversidade populacional. Sendo que, alguns genes codificadores de fatores de virulência são frequentemente

\section{Quadro 3. Comparação dos fatores de virulência de Staphylococcus spp. isoladas de leite mastítico de propriedades leiteiras localizadas no Sul-fluminense entre outubro/2009 e março/2011 por região de estudo}

\begin{tabular}{lcccc}
\hline \multicolumn{1}{c}{ Fatores de } & \multicolumn{4}{c}{ Regiões } \\
\cline { 2 - 5 } virulência & $\begin{array}{c}\text { Rio Claro } \\
(\mathrm{n}=135)\end{array}$ & $\begin{array}{c}\text { Piraí } \\
(\mathrm{n}=36)\end{array}$ & $\begin{array}{c}\text { Paracambi } \\
(\mathrm{n}=43)\end{array}$ & $\begin{array}{c}\text { Seropédica } \\
(\mathrm{n}=36)\end{array}$ \\
\hline “Slime" & 72,6 & 86,1 & 65,1 & 97,2 \\
icaA & 12,6 & 5,5 & 37,2 & 8,3 \\
icaD & 16,3 & 22,2 & 39,5 & 19,4 \\
SHA & 50,4 & 22,2 & 11,6 & 30,5 \\
Hemolisina & 8,9 & 2,8 & 27,9 & 22,2 \\
hla & 12,6 & 11,1 & 51,2 & 13,9 \\
hlb & 12,6 & 8,3 & 46,5 & 13,9 \\
Dnase & 25,2 & 36,1 & 27,9 & 25,0 \\
Caseinase & 60,7 & 88,9 & 62,8 & 69,4 \\
cap5 & 3,7 & 5,5 & 7,0 & 0,0 \\
cap8 & 0 & 0 & 14,0 & 11,1 \\
fnbA & 25,2 & 27,8 & 69,8 & 22,2 \\
fnbB & 4,4 & 0 & 11,6 & 0,0
\end{tabular}


detectados, enquanto outros são ausentes ou raramente estão presentes (Ote et al. 2011).

A partir dos resultados obtidos dos testes fenotípicos e genotípicos dos fatores de virulência foi possível estabelecer 105 perfis distintos, dificultando o estabelecimento de clones específicos circulantes em cada região. Apenas os ECNs com perfil cuja característica é a positividade para caseinase e produção de "slime" (Perfil 1) se apresentaram prevalentes em todas as regiões. Este perfil também foi detectado com elevada frequência em isolados de S.aureus da região de Rio Claro e ECPs das regiões de Rio Claro e Piraí, apontando para a importância destes fatores de virulência no desenvolvimento da mastite.

A tipagem molecular através da Eletroforese em Gel de Campo Pulsado (PFGE) foi realizada utilizando 50\% $(19 / 38)$ dos isolados de $S$. aureus deste estudo. Depois da digestão do DNA dos isolados com a enzima de restrição SmaI, foi possível a detecção de 6 perfis genéticos distintos (A-F). Os perfis A e B foram formados por 2 isolados cada um, os perfis C, D e E por 3 isolados cada um e o perfil F formado por um único isolado. Cinco (5) isolados não foram possíveis de tipar por esta técnica, destes, 4 isolados não foram cortados pela enzima Sma1 e 1 isolado quando submetido ao campo pulsante originou um perfil do tipo rastro. Esta técnica de genotipificação apresenta alto poder de discriminação e reprodutibilidade. Contudo, é uma técnica de custo elevado, onde são necessários, além de pessoal qualificado e materiais específicos, vários dias de análise (Dendani et al. 2010).

Foi possível observar uma acentuada diversidade de clones de $S$. aureus nas propriedades leiteiras avaliadas na região Sul-Fluminense do Estado do Rio de Janeiro, não tendo sido detectado um perfil predominante nos isolados estudados. Rabello (2007) detectaram 16 perfis ao analisar 106 cepas de $S$. aureus isolados de 9 fazendas distintas do Estado do Rio de Janeiro, sendo um dos perfis com seus subtipos predominante em $54,2 \%$ dos isolados e presente em $66,7 \%(6 / 9)$ propriedades avaliadas.

Ao correlacionar os perfis eletroforéticos do DNA cro- mossomal encontrados através do PFGE com os genes de virulência detectados por PCR, foi feito um agrupamento considerando os genes presentes em todos os isolados que apresentaram o mesmo perfil. Foi observado que os genes hla, hlb, cap5 e fnbA estavam presentes nos dois isolados que apresentaram o perfil A; os genes icaA, icaD, hla, hlb e $f n b A$ estavam presentes nos dois isolados que apresentaram o perfil B; os genes icaD, hla, $h l b, f n b A$ e fnbB estavam presentes nos três isolados que apresentaram o perfil C; os genes icaD, hla, hlb, e fnbA estavam presentes nos três isolados que apresentaram o perfil D; os genes hla, hlb e fnbA estavam presentes nos três isolados que apresentaram o perfil E. $\mathrm{O}$ perfil $\mathrm{F}$ foi verificado em apenas um isolado e apresentou prevalência dos mesmos de genes de virulência observado no perfil D (Quadro 4). De modo geral, foi observado que a presença ou ausência dos genes de virulência estudados não estavam relacionadas com os distintos perfis eletroforéticos. A grande diversidade genética observada nos isolados demonstra a existência de diversos clones circulantes. Foi observado ainda que os genes de virulência avaliados dentro do presente estudo não parecem contribuir para gerar discriminação entre os perfis obtidos.

Estudos epidemiológicos baseados no polimorfismo dos genes coa e spaA tem demonstrado que isolados de $S$. aureus podem ser divididos em subtipos (El-Sayed et al. 2006). No presente estudo, ao correlacionar a análise do polimorfismo dos genes spaA e coa com os perfis eletroforéticos obtidos por PFGE pode-se observar que apenas os perfis A e C, considerando o polimorfismo do gene spaA e os perfis $\mathrm{A}, \mathrm{B}$ e $\mathrm{D}$, considerando o polimorfismo do gene $c o a$, tiveram similitude, indicando um alto grau de heterogeneidade do gene coa e spaA em S. aureus (El-Sayed et al. 2006, Karahan \& Cetinkaya 2007). Já o gene agr não pode ser usado na discriminação das cepas de $S$. aureus neste estudo, pois amplificou fragmentos de mesmo tamanho (200 $\mathrm{pb})$.

O uso de técnicas moleculares adicionais e o estudo das demais cepas de estafilocócicas seriam necessários para um maior aprofundamento do estudo epidemiológico des-

\section{Quadro 4. Perfis encontrados através de PFGE e detecção dos genes de virulência por PCR em Staphylococcus spp. isoladas de leite mastítico de propriedades leiteiras da região Sul-fluminense de outubro/2009 a março/2011}

\begin{tabular}{|c|c|c|c|c|c|c|c|c|c|c|c|c|}
\hline \multirow{2}{*}{$\begin{array}{c}\text { Perfil } \\
\text { PFGE** }^{* *}\end{array}$} & \multirow[t]{2}{*}{ Isolados } & \multicolumn{11}{|c|}{ Genes de Virulência detectados por PCR ${ }^{* * *}$} \\
\hline & & $i c a A$ & icaD & hla & hlb & cap5 & cap8 & $f n b A$ & $f n b B$ & $\operatorname{spa} A\left(\mathrm{pb}^{*}\right)$ & $\operatorname{coa}\left(\mathrm{pb}^{*}\right)$ & $\operatorname{agr}\left(\mathrm{pb}^{*}\right)$ \\
\hline \multirow{2}{*}{ A } & $5 \mathrm{C}$ & $(-)$ & $(+)$ & $(+)$ & $(+)$ & $(+)$ & $(-)$ & $(+)$ & $(-)$ & 300 & 600 & 200 \\
\hline & 21B & $(+)$ & $(-)$ & $(+)$ & $(+)$ & $(+)$ & $(-)$ & $(+)$ & $(-)$ & 300 & 600 & 200 \\
\hline \multirow[t]{2}{*}{ B } & $225 \mathrm{~A}$ & $(+)$ & $(+)$ & $(+)$ & $(+)$ & $(-)$ & $(-)$ & $(+)$ & $(+)$ & 100 & 500 & 200 \\
\hline & $243 \mathrm{~A}$ & $(+)$ & $(+)$ & $(+)$ & $(+)$ & $(-)$ & $(-)$ & $(+)$ & $(-)$ & 300 & 500 & 200 \\
\hline \multirow[t]{3}{*}{ C } & $186 C$ & $(-)$ & $(+)$ & $(+)$ & $(+)$ & $(-)$ & $(-)$ & $(+)$ & $(+)$ & 100 & 500 & 200 \\
\hline & $241 \mathrm{C}$ & $(+)$ & $(+)$ & $(+)$ & $(+)$ & $(-)$ & $(-)$ & $(+)$ & $(+)$ & 100 & 600 & 200 \\
\hline & $251 \mathrm{~A}$ & $(+)$ & $(+)$ & $(+)$ & $(+)$ & $(-)$ & $(-)$ & $(+)$ & $(+)$ & 100 & 450 & 200 \\
\hline \multirow[t]{3}{*}{ D } & $147 \mathrm{~A}$ & $(-)$ & $(+)$ & $(+)$ & $(+)$ & $(-)$ & $(+)$ & $(+)$ & $(-)$ & 200 & 500 & 200 \\
\hline & $272 B$ & $(-)$ & $(+)$ & $(+)$ & $(+)$ & $(-)$ & $(-)$ & $(+)$ & $(-)$ & 200 & 500 & 200 \\
\hline & $273 \mathrm{C}$ & $(+)$ & $(+)$ & $(+)$ & $(+)$ & $(-)$ & $(-)$ & $(+)$ & $(+)$ & 300 & 500 & 200 \\
\hline \multirow[t]{3}{*}{ E } & $253 \mathrm{E}$ & $(+)$ & $(+)$ & $(+)$ & $(+)$ & $(-)$ & $(-)$ & $(+)$ & $(-)$ & 300 & 550 & 200 \\
\hline & $254 \mathrm{~B}$ & $(+)$ & $(-)$ & $(+)$ & $(+)$ & $(-)$ & $(+)$ & $(+)$ & $(-)$ & 320 & 600 & 200 \\
\hline & $252 \mathrm{~A}$ & $(-)$ & $(+)$ & $(+)$ & $(+)$ & $(-)$ & $(-)$ & $(+)$ & $(-)$ & 250 & 450 & 200 \\
\hline $\mathrm{F}$ & $245 B$ & $(-)$ & $(+)$ & $(+)$ & $(+)$ & $(-)$ & $(-)$ & $(+)$ & $(-)$ & 320 & 600 & 200 \\
\hline
\end{tabular}


tes clones, pois o conhecimento dos fatores de virulência de estafilococos isolados de rebanho leiteiro, pode ajudar a formular estratégias que reduzam a disseminação da infecção (Linehan et al. 2003).

\section{CONCLUSÕES}

Os fatores de virulência prevalentes em Staphylococcus spp. foram produção de "slime" e caseinase, sendo S. aureus a espécie que apresentou maior expressão fenotípica de fatores de virulência, bem como maior amplificação de genes relacionados à codificação desses fatores, o que ressalta o potencial patogênico deste microrganismo.

A região de Paracambi apresentou elevada frequência de todos os fatores de virulência quando comparado às outras regiões de estudo. 0 grande número de perfis gerados a partir dos testes fenotípicos e genotípicos de detecção dos fatores de virulência dificultou o estabelecimento de clones específicos circulantes em cada região.

A tipagem molecular através da PFGE de $S$. aureus não detectou um perfil eletroforético predominante e a presença ou ausência dos genes de virulência estudados não contribuiu como critério discriminatório entre os perfis obtidos, confirmando a acentuada diversidade de clones circulantes desta espécie nas propriedades leiteiras avaliadas.

Agradecimentos.- À Coordenação de Aperfeiçoamento de Pessoal de Nível Supeior (CAPES) e Fundação de Amparo à Pesquisa do Estado do Rio de Janeiro (FAPERJ) pelo apoio financeiro.

\section{REFERÊNCIAS}

Aarestrup F.M., Dangler C.A. \& Sordillo L.M. 1995. Prevalence of coagulase gene polymorphism in Staphylococcus aureus isolates causing bovine mastitis. Can. J. Vet. Res. 59:124-128.

Bannerman T.L. 2003. Staphylococcus, Micrococcus, and other catalase-positive cocci that grow aerobically, p.384-404. In: Murray P.R., Baron E.J., Jorgensen J.H., Pfaller M.A. \& Yolken R.H. (Eds), Manual of Clinical Microbiology. American Society Microbiology, Washington, DC.

Bannoehr J., Franco A., Iurescia M., Battisti A. \& Fitzgerald J.R. 2009. Molecular Diagnostic Identification of Staphylococcus pseudintermedius. J. Clin. Microbiol. 47(2):469-471.

Cerca N., Jefferson K.K., Litrán T.M., Pier D.B., Quintos C.K., Goldman D.A., Azeredo J. \& Pier G.B. 2007. Molecular basis for preferential protective efficacy of antibodies directed to the poorly acetylated form of staphylococcal poly- $n$-acetyl-_-(1-6)-glucosamine. Infect. Immun. 75(7):34063413.

Chapman G., Berens C., Peters A. \& Curcio L. 1934. Coagulase and hemolysin tests as measures of the pathogenicity of staphylococci. J. Bacteriol. 28(4):343-363.

Christensen G.D., Simpson W.A., Younger J.J., Baddour M.L., Barret F.F., Melton D.M. \& Beachey E.H. 1985. Adherence of coagulase-active staphylococci to plastic tissue culture plates: A quantitative model for the adherence of staphylococci to medical devices. J. Clin. Microbiol. 22(6):996-1006.

Citak S., Varlik O. \& Gundogan N. 2003. Slime production and DNase activity of Staphylococci isolated from raw milk. J. Food Safety 23:281-288.

Coelho S.M.S. 2008. Caracterização fenotípica e genotípica de fatores de virulência e resistência à oxacilina em Staphylococcus spp. coagulase-positivos isolados de mastite bovina. Tese de doutorado em Ciências Veterinárias, Departamento de Microbiologia e Imunologia Veterinária, Universidade Federal Rural do Rio de Janeiro, RJ. 77p.

Coelho S.M.O., Pereira I.A., Soares L.C., Pribul B.R. \& Souza M.M.S. 2011. Short communication: Profile of virulence factors of Staphylococcus aureus isolated from subclinical bovine mastitis in the state of Rio de Janeiro, Brazil. J. Dairy Sci. 94(7):3305-3310.

Cruz R.S. 2008. Análise do efeito do lócus agr sobre a formação de biofilme em cepas de Staphylococcus aureus. Tese de Doutorado em Ciências Biológicas (Microbiologia), Instituto de Microbiologia Professor Paulo de Góes, Universidade Federal do Rio de Janeiro, RJ. 96p.

Cucarella C., Solano C., Valle J., Amorena B., Lasa I.N.I. \& Penade's J.R. 2001. Bap, a Staphylococcus aureus Surface Protein Involved in Biofilm Formation. J. Bacteriology. 183(9):2888-2896.

Daum R.S. \& Spelberg B. 2011. Progress toward a Staphylococcus aureus vaccine. Clin. Infect. Dis. Advances. DOI: 10.1093/cid/cir828.

Dego K.O., Van Dijk J.E. \& Nederbragt H. 2002. Factors involved in the early pathogenesis of bovine Staphylococcus aureus mastitis with emphasis on bacterial adhesion and invasion: A review. Vet. Microbiol. 24:181198.

Dendani Z., Arcangioli M.A., Bezille P., Ouzrout R. \& Sellami N.L. 2010. Genotyping of Staphylococcus aureus isolated from bovine clinical mastitis by Pulsed-Field Gel Electrophoresis (PFGE). J. Anim. Vet. Advances 9(1):5-11.

Demo M. 1996. Caracterizacion y studios de patogenicidad de cepas dela genero Staphylococcus asiladas de leches mastiticas. Tese de Doutorado, Instituto de Microbiologia, Universidad Nacional de Rio Cuarto, Argentina.

Dobinsky S., Kiel K., Rohde H., Bartscht K., Knobloch J.K.M., Horstkotte M.A. \& Mack D. 2003. Glucose-related dissociation between icaADBC transcription and biofilm expression by Staphylococcus epidermidis: Evidence for an additional factor required for polysaccharide intercellular adhesin synthesis. J. Bacteriol. 185(9):2879-2886.

El-Sayed A., Alber J., Lammer C., Jager S., Wolter W. \& Vázquez H.C. 2006. Comparative study on genotypic properties of Staphylococcus aureus isolated from clinical and subclinical mastitis in Mexico. Vet. Méx. 37(2):165-179.

Ferreira L.M., Nader Filho A., Oliveira E., Zafalon L.F. \& Souza V. 2006. Variabilidades fenotípica e genotípica de estirpes de Staphylococcus aureus isoladas em casos de mastite subclínica bovina. Ciência Rural 36(4):1228-1234.

Freitas M.F.L., Pinheiro Júnior J.W., Stamford T.L.M., Rabelo S.S.A., Silva D.R., Silveira Filho V.M., Santos F.G.B., Sena M.J. \& Mota R.A. 2005. Perfil de sensibilidade antimicrobiana in vitro de Staphylococcus coagulase positivos isolados de leite de vacas com mastite no agreste do estado de Pernambuco. Arqs Inst. Biológico, São Paulo, 72(2):171-177.

Frenay H., Bunschoten A., Schouls L., Van Leeuwen W., Vandenbroucke-Grauls C., Verhoef J. \& Mooi F. 1996. Molecular typing of methicillin-resistant Staphylococcus aureus on the basis of protein A gene polymorphism. Eur. J Clin. Microbiol. Infect. Dis. 15:60-64.

Gad G.F.M., El-Feky M.A., El-Rehewy M.S., Hassan M.A., Abolella H. \& El-Baky R.M. 2009. Detection of icaA, icaD genes and biofilm production by Staphylococcus aureus and Staphylococcus epidermidis isolated from urinary tract catheterized patients. J. Infect. Dev. Countries 3(5):342351.

Gómez M., Seaghdha M.O. \& Prince A.S. 2007. Staphylococcus aureus protein A activates TACE through EGFR-dependent signaling. EMBO Journal 26:701-709.

Greene C., McDevitt D., Francois P., Vaudaux P., Lew D.P. \& Foster T.J. 1995. Adhesion properties of mutants of Stapbylococcus aureus defective in fibronectin-binding proteins and studies on expression of $\mathrm{f} n \mathrm{~b}$ genes. Mol. Microbiol. 17:1143-1152.

Handke L.D., Slater S.R., Conlon K.M., O’Donnell S.T., Olson M.E., Bryant K.A., Rupp M.E., O'Gara J.P. \& Fey P.D. 2007. SigmaB and SarA independently regulate polysaccharide intercellular adhesin production in Staphylococcus epidermidis. Can. J. Microbiol. 53:82-91.

Karahan M. \& Cetinkaya B. 2007. Coagulase gene polymorphisms detected by PCR in Staphylococcus aureus isolated from subclinical bovine mastitis in Turkey. Vet. Journal 174(2):428-431.

Koneman E.W., Allen S.D., Janda W.M, Schreckenberger P.C. \& Winn Jr 2008. Diagnóstico Microbiológico. 6 $6^{\underline{a}}$ ed. Editora MEDS, Rio de Janeiro. 
Krepsky N., Ferreira R.B.R., Nunes A.P.F., Lins U.G.C., Silva Filho F.C., Mattos-Guaraldi A.L. \& Netto-dos Santos K.R. 2003. Cell surface hydrophobicity and slime production of Staphylococcus epidermidis Brazilian isolates. Curr. Microbiol. 46:280-286.

Larsen H.D., Aarestup F.M. \& Jensen N.E. 2002. Geographical variation in the presence of genes encoding superantigenic exotoxins and $\beta$-hemolysin among Staphylococcus aureus isolated from bovine mastitis in Europe and USA. Vet. Microbiol. 85:61-67.

Linehan D., Etienne J. \& Sheehan D. 2003. Relationship between haemolytic and sphingomyelinase activities in a partially purified $\beta$-like toxin from Staphylococcus schleiferi. FEMS Immunol. Med. Microbiol. 36(1/2):95-102.

Melchior M.B., Vaarkamp H. \& Fink-Gremmels J. 2005. Biofilms: A role in recurrent mastitis infections? Vet. Journal 171:398-407.

Nilsson I.-M., Hartford O., Foster T. \& Tarkowski A. 1999. Alpha-toxin and gamma-toxin jointly promote Staphylococcus aureus virulence in murine septic arthritis. Infect. Immun. 67:1045-1049.

Novick R.P. \& Jiang D. 2003. The staphylococcal saeRS system coordinates environmental signals with agr quorum sensing. Microbiology 149:2709-2717.

O’Riordan K. \& Lee J.C. 2004. Staphylococcus aureus capsular polysaccharides. Clin. Microbiol. Rev. 17(1):218-234.

Oliveira M., Bexiga R., Nunes S.F., Carneiro C., Cavaco L.M., Bernardo F. \& Vilela C.L. 2006. Biofilm-forming ability profiling of Staphylococcus aureus and Staphylococcus epidermidis mastitis isolates. Vet. Microbiol. 118:133-140.

Ote I., Taminiau B., Duprez J.-N., Dizier I. \& Mainil J.G. 2011. Genotypic characterization by polymerase chain reaction of Staphylococcus aureus isolates associated with bovine mastitis. Vet. Microbiol. 153: 285-292.

Park P.W., Foster T.J., Nishi E., Duncan S.J., Klagsbrun M. \& Chen Y. 2004. Activation of syndecan-1 ectodomain shedding by Staphylococcus aureus $\alpha$-toxin and $\beta$-toxin. J. Biol. Chem. 279(1):251-258.

Peacock S.J., Day N.P.J., Thomas M.G., Berendt A.R. \& Foster T.J. 2000. Clinical isolates of Staphylococcus aureus exhibit diversity in fnb genes and adhesion to human fibronectin. J. Infection 41:23-31.

Pitkala A., Haveri M., Pyörälä S., Myllys V. \& Honkanen-Buzalski T. 2004. Bovine mastitis in Finland 2001: prevalence, distribution of bacteria, and antimicrobial resistance. J. Dairy Sci. 87:2433-2441.

Pyorala S. \& Taponen S. 2009. Coagulase-negative staphylococci: Emerging mastitis pathogens. Vet. Microbiol. 134:3-8.

Rabello R.F. 2007. Diversidade genética e genes de virulência de amostras de Staphylococcus aureus isoladas de mastite bovina no Estado do Rio de Janeiro. Tese de Doutorado em Ciências Biológicas (Microbiologia), Instituto de Microbiologia Professor Paulo de Góes, Universidade Federal do Rio de Janeiro, RJ. 161p.

Reinoso E.B. 2004. Análisis epidemiológico y molecuar de cepas de Staphylococcus aureus de distintos orígenes. Tese de Doutorado, Instituto de Microbiologia, Universidad Nacional de Rio Cuarto. 199p.

Reinoso E.B., El-Sayed A., Lammler C., Bognia C. \& Zschockc M. 2008. Genotyping of Staphylococcus aureus isolated from humans, bovine subclinical mastitis and food samples in Argentina. Microbiol. Res. 163:314-322.
Sabersheikh S. \& Saunders N.A. 2004. Quantification of virulence-associated gene transcripts in epidemic methicillin resistant Staphylococcus aureus by real-time PCR. Mol. Cell Probes 18(1):23-31.

Sambrook J., Fritsch E.F. \& Maniatis T. 2002. Molecular Cloning: A laboratory manual. Cold Spring Harbor Lab. Press, New York.

Santos C.D.M. 2006. Staphylococcus sp e enterobactérias isoladas de mastite recorrente em oito rebanhos da região de Uberlândia/MG: perfil de suscetibilidade aos antimicrobianos. Mestrado em Produção Animal, Faculdade de Medicina Veterinária, Universidade Federal de Uberlândia, MG. 69p.

Santos L.L. 2008. Staphylococcus coagulase negativo como agente de mamite em rebanhos bovinos leiteiros da região sul do Estado de Minas Gerais. Dissertação de Mestrado em Medicina Veterinária, Escola de Veterinária, Universidade Federal de Minas Gerais, Belo Horizonte. 40p.

Silva N. \& Cardoso H.F.T. 2000. Produção de toxinas hemolíticas por amostras de Staphylococcus aureus isoladas de mastite bovina. Vet. Notícias 6(2):63-67.

Silva E.C.B.F., Maciel M.A.V., Melo F.L., Antas M.G.C., Neto A.M.B. \& Rabelo M.A. 2007. Staphylococcus aureus: aspectos biológicos e patogênicos. Anais Fac. Med. Univ. Fed. Pernambuco, Recife, 52(2):168-172.

Silva W.P., Silva A.J., Macedo M.R.P., Araújo M.R., Mata M.M. \& Gandra E.A. 2003. Identification of Staphylococcus aureus, S. intermedius and S. hyicus by PCR amplification of coa and nuc genes. Braz. J. Microbiol. 34(Suppl.1):125-127.

Straub J.A., Hertel C. \& Hammes W.P. 1999. A 23S RNAr-targeted polymerase chain reaction-based system for detection of Staphylococcus aureus in meat started cultures and dairy products. J. Food Prot. 62:1150-1156.

Taponen S., Simojoki H., Haveri M., Larsen H.D. \& Pyorala S. 2006. Clinical characteristics and persistence of bovine mastitis caused by different species of coagulase-negative staphylococci identified with API or AFLP. Vet. Microbiol. 115:199-207.

Tollersrud T., Kenny K., Reitz Jr A.J. \& Lee J.C. 2000. Genetic and serologic evaluation of capsule production by bovine mammary isolates of Staphylococcus aureus and other Staphylococcus spp. from Europe and the United States. J. Clin. Microbiol. 38:2998-3003.

Vasudevan P., Nair M.K.M., Annamalai T. \& Venkitanarayana K.S. 2003. Phenotypic and Genotipic characterization of bovine mastitis isolates of Staphylococcus aureus for biofilm formation. Vet. Microbiol. 92:179-185.

Watts J. 1988. Etiological agents of bovine mastitis. Vet. Microbiol. 16:4146.

Zafalon L.F., Nader Filho A., Carvalho M.R.B. \& Lima T.M.A. de. 2008. Influência da mastite subclínica bovina sobre as frações protéicas do leite. Arqs Inst. Biológico, São Paulo, 75(2):135-140.

Zhang K., Sparling J., Chow B.L., Elsayed S., Hussain Z., Church D.L., Gregson D.B., Louie T. \& Conly J.M. 2004. New quadriplex PCR assay for detection of methicillin and mupirocin resistance and simultaneous discrimination of Staphylococcus aureus from coagulase-negative Staphylococci. J. Clin. Microbiol. 42(11):4947-4955.

Zhao L., Xue T., Shang F., Sun H. \& Sun B. 2010. Staphylococcus aureus AI-2 quorum sensing associates with the KdpDE two-component system to regulate capsular polysaccharide synthesis and virulence. Infect. Immun. 78(8):3506-3515. 